\title{
Aplicación del modelo factorial para identificar las causas y efectos del comercio informal
}

\author{
Application of the factorial model to identify the \\ causes and effects of informal trade
}

Quispe Fernandez, Gabith Miriam Universidad Nacional de Chimborazo (Ecuador) gabithmiriam@gmail.com

Villa Villa, Marlon Vicente Universidad Nacional de Chimborazo (Ecuador) mvilla@unach.edu.ec

Velarde, Rodrigo

Universidad Nacional de Chimborazo (Ecuador)

rodrigo.velarde@hotmail.es

Revista Cumbres Vol.5 №2

Versión impresa ISSN 1390-9541

Versión electrónica ISSN 1390-3365

http://investigacion.utmachala.edu.ec/revistas/index.php/Cumbres 


\title{
RESUMEN
}

El objetivo de la investigación determina las causas y efectos del comercio informal aplicado al caso de Ecuador - Ciudad de Riobamba. Usa como metodología el método inductivo, es de un nivel causal - estadístico. La población corresponde a 3.600 comerciantes y se aplicó la encuesta a una muestra de 310. Se aplica el análisis multivariante de factorización y regresión lineal. Los resultados de la investigación muestran que la relación de la actividad del comercio informal no es significativa con las variables, como el estado civil, edad, ingreso económico y el nivel de instrucción. Asimismo, se determina a través del análisis factorial, los precios de los productos, la migración, el pago de impuestos, las necesidades básicas, la disponibilidad de espacios públicos son los principales factores que inciden en la actividad aunque no se observan como variables determinantes. Por tanto, se concluye que el comercio informal se relaciona con las características generales de población y de la actividad comercial; y genera como consecuencia la reducción en la recaudación de impuestos.

Palabras clave: Comercio informal, análisis multivariante, factores.

\begin{abstract}
The objective of the research determines the causes and effects of informal trade in the case of Ecuador - City of Riobamba. It uses the inductive method as a methodology, it is of a causal - statistical level. The population corresponds to 3,600 merchants and the survey is applied to a sample of 310 . The multivariate factorization and linear regression analysis is applied. The results of the research show that the relationship of informal trade activity is not significant with the variables, such as marital status, age, economic income and educational level. Likewise, it is determined through the factorial analysis, the prices of the products, the migration, the payment of taxes, the basic necessities, the availability of public spaces, the factors that affect the activity although they are not observed as determining variables. Therefore, it is concluded that informal trade is related to the general characteristics of the population and commercial activity; and generates as a consequence the reduction in tax collection.
\end{abstract}

Keywords: Informal trade, multivariate analysis, factors. 


\section{INTRODUCCIÓN}

De acuerdo a las investigaciones realizadas sobre la actividad informal, la Organización Internacional del Trabajo (OIT) (2002, 2014,2016), del Banco mundial (2013) y otros, muestran "que los trabajadores informales se enfrentan habitualmente a riesgos más elevados de pobreza que los trabajadores de la economía formal y que el trabajo en la economía informal y el hecho de ser pobre y vulnerable tiene una relación alta" citado en Quispe, et.al. ( 2018, pág. 4). Es asi que, la informalidad se entiende como "un fenómeno que hace algunos años se consideraba un rasgo particular de algunas economías, especialmente de aquellas más atrasadas, cuya existencia desbordaba el arquetipo de cómo deberían funcionar las economías modernas" (Sandoval, 2014, pág. 11). Los datos muestran que la tasa desocupación según OIT, alcanza en América Latina para el año 2017 el 9.9\%, en el caso de Ecuador el 4.3\% (OIT, 2018, pág. 7). Así, los indicadores de empleabilidad en Ecuador muestran que la actividad en el sector informal alcanza el $47.5 \%$ a diferencia del sector formal que alcanza el $46, \%$; y otros indicadores que se presenta en el figura 1.

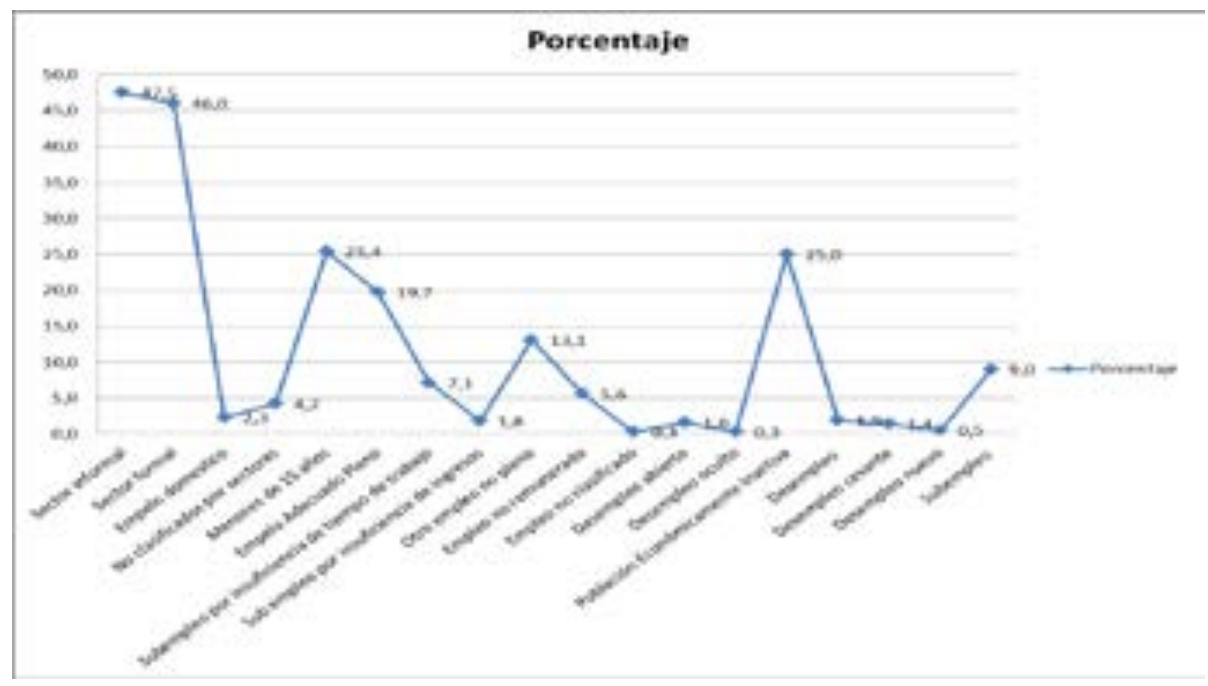

Figura 1. Indicadores de empleabilidad en Ecuador

Asimismo, los datos muestran que en la actualidad el comercio es una actividad formal, que representa en el caso de Ecuador en el año 2016 el 32,2\% superior al 26,8\% con relación a América Latina, siendo la actividad mayor desarrollada por la población económicamente activa de género femenino que representa el $42,4 \%$ con relación a los varones que alcanza el $25 \%$, seguido por las actividades relacionada con los servicios,. como se puede observar en la tabla 1. Sin embargo, a pesar de constituirse la actividad comercial como formal, también se puede observar que el mismo fue incrementándose en todas la ciudades de Ecuador principalmente alrededor de los mercados, con la venta de diferentes productos, desde agrícolas hasta la manufactura, principalmente relacionada con prendas de vestir. 
Tabla 1. Actividades que desarrolla la población económica

\begin{tabular}{|c|c|c|c|c|c|c|c|c|c|c|}
\hline $\begin{array}{l}\text { Países, } \\
\text { año y } \\
\text { sexo }\end{array}$ & Total & $\begin{array}{l}\text { Agri- } \\
\text { cul- } \\
\text { tura, } \\
\text { pesca } \\
\text { y mi- } \\
\text { nas }\end{array}$ & $\begin{array}{l}\text { Elec- } \\
\text { trici- } \\
\text { dad, } \\
\text { gas y } \\
\text { agua }\end{array}$ & $\begin{array}{l}\text { Indus- } \\
\text { tria } \\
\text { manu- } \\
\text { factu- } \\
\text { rera }\end{array}$ & $\begin{array}{l}\text { Cons- } \\
\text { truc- } \\
\text { ción }\end{array}$ & $\begin{array}{l}\text { Co- } \\
\text { mer- } \\
\text { cio }\end{array}$ & $\begin{array}{l}\text { Trans- } \\
\text { porte, } \\
\text { alma- } \\
\text { cena- } \\
\text { miento } \\
\text { y comu- } \\
\text { nicacio- } \\
\text { nes }\end{array}$ & $\begin{array}{l}\text { Esta- } \\
\text { bleci- } \\
\text { mien- } \\
\text { tos } \\
\text { finan- } \\
\text { cieros }\end{array}$ & $\begin{array}{l}\text { Ser- } \\
\text { vicios } \\
\text { comu- } \\
\text { nales, } \\
\text { socia- } \\
\text { les y } \\
\text { per- } \\
\text { sona- } \\
\text { les }\end{array}$ & $\begin{array}{l}\text { Acti- } \\
\text { vida- } \\
\text { des } \\
\text { no } \\
\text { es- } \\
\text { peci- } \\
\text { fica- } \\
\text { das }\end{array}$ \\
\hline $\begin{array}{l}\text { Ecuador } \\
\text { e/ }\end{array}$ & & & & & & & & & & \\
\hline $\begin{array}{llll}2 & 0 & 1 & 1 \\
\text { Total } & & \end{array}$ & 100,0 & 8,1 & 0,6 & 13,2 & 6,7 & 34,1 & 8,1 & 7,7 & 21,5 & 0,0 \\
\hline bre ${ }^{\text {Hom- }}$ & 100,0 & 11,2 & 0,8 & 14,1 & 10,8 & 28,0 & 11,8 & 8,2 & 15,0 & 0,0 \\
\hline jer $\mathrm{Mu}^{-}$ & 100,0 & 3,7 & 0,3 & 11,8 & 0,9 & 42,9 & 2,8 & 6,9 & 30,8 & 0,0 \\
\hline $\begin{array}{llll}2 & 0 & 1 & 2 \\
\text { Total } & \end{array}$ & 100,0 & 7,6 & 0,6 & 12,9 & 6,9 & 33,9 & 8,0 & 8,6 & 21,6 & 0,0 \\
\hline Hombre & 100,0 & 10,3 & 0,8 & 14,1 & 11,0 & 27,3 & 12,2 & 9,5 & 14,8 & 0,0 \\
\hline jer $\mathrm{Mu}-$ & 100,0 & 3,9 & 0,3 & 11,3 & 1,0 & 43,1 & 2,2 & 7,3 & 30,9 & 0,0 \\
\hline $\begin{array}{llll}2 & 0 & 1 & 3 \\
\text { Total } & & \end{array}$ & 100,0 & 7,8 & 0,6 & 13,3 & 8,1 & 30,1 & 8,4 & 8,2 & 23,5 & 0,0 \\
\hline Hombre & 100,0 & 10,4 & 0,7 & 14,4 & 13,0 & 24,6 & 12,1 & 8,2 & 16,6 & 0,0 \\
\hline jer $\quad \mathrm{Mu}-$ & 100,0 & 3,9 & 0,4 & 11,7 & 0,9 & 38,1 & 3,0 & 8,2 & 33,8 & 0,0 \\
\hline $\begin{array}{llll}2 & 0 & 1 & 4 \\
\text { Total } & & \end{array}$ & 100,0 & 9,0 & 0,6 & 12,6 & 7,6 & 31,2 & 8,7 & 7,2 & 23,2 & 0,0 \\
\hline Hombre & 100,0 & 11,7 & 0,7 & 14,4 & 12,5 & 24,6 & 12,5 & 7,8 & 15,8 & 0,0 \\
\hline jer $\mathrm{Mu}$ & 100,0 & 5,0 & 0,3 & 10,1 & 0,5 & 40,7 & 3,1 & 6,4 & 34,0 & 0,0 \\
\hline $\begin{array}{llll}2 & 0 & 1 & 5 \\
\text { Total } & \end{array}$ & 100,0 & 8,6 & 0,6 & 12,2 & 8,0 & 31,5 & 9,2 & 7,3 & 22,7 & 0,0 \\
\hline Hombre & 100,0 & 11,5 & 0,9 & 13,5 & 12,9 & 24,8 & 13,5 & 7,5 & 15,3 & 0,0 \\
\hline jer $\mathrm{Mu}-$ & 100,0 & 4,4 & 0,2 & 10,3 & 0,8 & 41,0 & 3,0 & 7,0 & 33,2 & 0,0 \\
\hline $\begin{array}{llll}2 & 0 & 1 & 6 \\
\text { Total } & & \end{array}$ & 100,0 & 8,8 & 0,6 & 12,9 & 7,9 & 32,3 & 8,4 & 6,9 & 22,1 & 0,0 \\
\hline Hombre & 100,0 & 11,3 & 0,9 & 14,5 & 13,1 & 25,0 & 12,7 & 7,4 & 14,9 & 0,0 \\
\hline jer $\mathrm{Mu}-$ & 100,0 & 5,4 & 0,2 & 10,7 & 0,7 & 42,4 & 2,4 & 6,1 & 32,1 & 0,0 \\
\hline
\end{tabular}

Fuente: Elaboración propia con base en datos de la OIT, 2018

Desde esta perspectiva en la economía informal se puede encontrar como actividad informal al comercio informal que se desarrollan en los países, entendiendo que el comercio informal" es aquel que no se rige por las normativas y leyes relativas a las transacciones de bienes y o servicios en la sociedad. El comercio informal, librado a las calles y espacios públicos, sobre la base de mercancía, por lo general de bajo costo, muy dinámicos en cuanto 
a su oferta, constituye la actividad central donde actúan miles de personas. (Castillo Garcia, 2014, pág. 4). Hernandez \& De la Roca (2006, pág. 65) menciona "que las actividades informales reducen la base impositiva, con lo cual impiden un financiamiento sostenible de los bienes públicos y de protección social... una elevada dimensión del sector informal suele afectar, de manera negativa, la evolución de la actividad económica". Por tanto, La evasión tributaria es una acción ilícita, es decir, implica la violación de la ley tributaria (su letra y su espíritu). Por lo tanto, la evasión tributaria tiene una serie de consecuencias jurídicas para sus evasores, pues implica la transgresión de la legislación tributaria vigente. Para conseguir este propósito, entre otras cosas, los contribuyentes hacen una declaración falsa o simplemente ocultan la información sobre la base del impuesto que deben declarar y el monto del tributo a pagar a la autoridad tributaria. (Henríquez, 2015).

También, la evasión cuando el sujeto, siendo contribuyente de algún impuesto determinado, y habiendo efectuado operaciones que implican la causación y pago de dicho impuesto, se abstiene de cumplir. "Esto sí es violatorio de la ley, puesto que la obligación existe, se ha dado, y el sujeto no cumple con ella“. (León, 2014), La evasión fiscal, es la conducta ilícita por el ocultamiento de todo o parte del hecho imponible, que realiza el sujeto pasivo, para evitar el pago de la deuda tributaria, estando obligado por la ley. (Rua, 2016). Por tanto, la evasión tributaria es un hecho que preocupa a todos los países del mundo, por los efectos que ha producido tales como la disminución en los ingresos, déficit fiscal y disminución de la inversión privada. En Ecuador existen brechas de recaudación basadas en análisis comparativos de impuestos causados e impuestos generados calculados a partir de las cuentas nacionales, siendo la brecha de evasión de las personas naturales la más amplia; información que relaciona el nivel de cultura tributaria y los controles de evasión realizados por la Administración Tributaria del Ecuador (Ordoñez, Abril de 2010)

Así, desde este punto de vista, tras un recorrido de revisión documental bibliográfico se puede identificar estudios relacionados al tema, donde se observa la relación que existe entre la actividad de comercio informal y la evasión tributaria, como se presenta en el tabla 2.

Tabla 2. La evasión Tributaria en Latinoamérica y el Ecuador

\begin{tabular}{|l|l|l|}
\hline AUTOR & TITULO DE LA INVESTIGACIÓN & CONCLUSIONES \\
\hline (Quispe, y otros, 2018) & $\begin{array}{l}\text { Causas del comercio informal y } \\
\text { la evasión tributaria en ciudades } \\
\text { intermedias }\end{array}$ & $\begin{array}{l}\text { El comercio informal contribuye en } \\
\text { la evasión tributaria y; la migración, } \\
\text { desempleo, crecimiento poblacional, } \\
\text { capital de inversión, desconocimiento } \\
\text { de las normas tributarias, desconoci- } \\
\text { miento de la regulación del uso público } \\
\text { son las causas del incremento del } \\
\text { comercio informal }\end{array}$ \\
\hline (Romero, 2018) & $\begin{array}{l}\text { Las brechas de recaudación tributa- } \\
\text { ria del impuesto al valor agregado } \\
\text { en el sector societario y su impacto } \\
\text { en el presupuesto general del estado } \\
\text { ecuatoriano }\end{array}$ & $\begin{array}{l}\text { La evasión y elusión tributaria siguen } \\
\text { siendo los principales medios que tie- } \\
\text { nen los contribuyentes en general para } \\
\text { no cancelar impuestos, no obstante } \\
\text { los esfuerzos del Servicio de Rentas } \\
\text { Internas han sido efectivos para de- } \\
\text { tectar irregularidades y alcanzar altos } \\
\text { niveles de cumplimiento tributario por } \\
\text { concepto de IVA de sociedades. }\end{array}$ \\
\hline
\end{tabular}




\begin{tabular}{|c|c|c|}
\hline $\begin{array}{l}\text { (Real \& Navarrete, } \\
\text { 2018) }\end{array}$ & $\begin{array}{l}\text { Los Paraísos Fiscales y La Elusión } \\
\text { Tributaria en el Ecuador }\end{array}$ & $\begin{array}{l}\text { La elusión fiscal afecta a la gran ma- } \\
\text { yoría de los ciudadanos, debido a que } \\
\text { no se pueden cumplir los programas } \\
\text { de educación, salud, vialidad, casas y } \\
\text { otros, que forman parte de los dere- } \\
\text { chos consagrados en la constitución } \\
\text { ecuatoriana. }\end{array}$ \\
\hline $\begin{array}{l}\text { (Delgado, Abambari, \& } \\
\text { Moreira , 2017) }\end{array}$ & $\begin{array}{l}\text { Efectos de la evasión en el impuesto } \\
\text { a la renta, originado por el contra- } \\
\text { bando de mercaderías en la frontera } \\
\text { Sur }\end{array}$ & $\begin{array}{l}\text { El contrabando es un fenómeno mun- } \\
\text { dial que tiene sus implicaciones entre } \\
\text { otros, en el desempleo y la baja cultura } \\
\text { tributaria, que por la falta de gestión } \\
\text { del Estado para controlarlo se dejaron } \\
\text { de recaudar millones de dólares por } \\
\text { concepto de tributos aduaneros e } \\
\text { impuesto a la renta. }\end{array}$ \\
\hline (Suárez, 2017) & $\begin{array}{l}\text { Motivos y consecuencias de la } \\
\text { evasión tributaria en las MYPES en } \\
\text { el emporio comercial Gamarra, La } \\
\text { Victoria-Lima }\end{array}$ & $\begin{array}{l}\text { La evasión implica que se ponga en } \\
\text { riesgo en cumplimiento de las respon- } \\
\text { sabilidades laborales, puesto que al } \\
\text { ser detectadas ocasionan multas y san- } \\
\text { ciones que pueden cerrar el negocio, } \\
\text { dejando al personal sin oportunidad de } \\
\text { seguir laborando. }\end{array}$ \\
\hline (Paredes, 2016) & $\begin{array}{l}\text { Evasión tributaria vs. Mecanismos } \\
\text { de control implementados por la } \\
\text { administración pública }\end{array}$ & $\begin{array}{l}\text { Es importante considerar la relación } \\
\text { de intercambio de bienes y servicios } \\
\text { versus los impuestos pagados; en este } \\
\text { contexto los contribuyentes, evaden } \\
\text { menos cuando consideran que reciben } \\
\text { bienes y servicios que retribuyen los } \\
\text { impuestos pagados. Los resultados } \\
\text { arrojaron que el 38,9\% de los contribu- } \\
\text { yentes aún evaden impuestos. }\end{array}$ \\
\hline $\begin{array}{l}\text { (Merchán \& Velás- } \\
\text { quez, 2015) }\end{array}$ & $\begin{array}{l}\text { La evasión y elusión tributaria de } \\
\text { las MYPE en las empresas del sector } \\
\text { comercio-rubro abarrotes del distri- } \\
\text { to de Chimbote, } 2014\end{array}$ & $\begin{array}{l}\text { La evasión y elusión tributaria solo se } \\
\text { evitarán cuando se tome conciencia de } \\
\text { que la tributación no es una obligación } \\
\text { sino un deber con el Estado peruano }\end{array}$ \\
\hline (Quintanilla, 2014) & $\begin{array}{l}\text { La evasión tributaria y su incidencia } \\
\text { en la Recaudación fiscal en el Perú y } \\
\text { Latinoamérica }\end{array}$ & $\begin{array}{l}\text { Permite establecer que la evasión } \\
\text { de impuestos, ocasiona disminución } \\
\text { en el nivel de fondos que maneja el } \\
\text { gobierno. }\end{array}$ \\
\hline
\end{tabular}

Así, de esta forma el objetivo de la investigación determina las causas y efectos del comercio informal aplicado al caso de Ecuador - Ciudad de Riobamba.

Ase plantea como hipótesis de trabajo $\mathrm{H} 1$ = las razones que tienen los comerciantes para iniciar una actividad informal está relacionada con ser independiente; por necesidad; y no encontró trabajo asalariado.

\section{MATERIALES Y MÉTODOS}

Usa como metodología el método inductivo, es de un nivel causal - estadístico. La población corresponde a 3.600 comerciantes y se aplicó la encuesta a una muestra de 310. Se aplica el análisis multivariante de factorización y regresión lineal. 


\section{RESULTADOS}

\section{Características sociales del comerciante informal}

Los resultados de la investigación permiten identificar que las personas que se dedican al comercio informal son del género femenino en un $74 \%$ y los varones en un $25,2 \%$. Se encuentran entre las edades de 27 a $64 \%$ en un 81,94 $\%$, en un 14,52\% entre las edades 15 a 26 años y el 3,55\% entre las edades de 65 a más años, lo que quiere decir que las mujeres son las que desarrollan la actividad del comercio informal y son las que terminan considerando como fuente de empleo y generación de ingreso. Asimismo, quienes se dedican a la actividad del comercio informal son personas casadas en un $65,2 \%$ y solteros en $15,5 \%$, divorciado un $8,1 \%$, unión libre el 7,7\% y viudos en un 3,5\%. El número de familia está constituido en promedio de cuatro personas. Tienen una formación en su mayoría el nivel primario $(43,9 \%)$ y secundario $(42,6 \%)$ y menor grado el nivel superior (9.4\%). Los que se dedican a esta actividad son las que radican en zonas urbanas en un $68,4 \%$ y rurales en un $31,6 \%$.

\section{Características económicas del comercio informal}

El comerciante informal al constituirse en una persona dedica a la venta de producto o servicios, los ingresos que obtiene por dicha actividad en un $82,6 \%$ se encuentra en el intervalo de 1 a $500 \$$ us; $11,6 \%$ de 501 a $1000 \$$ us; $4,8 \%$ de 1001 a 1500 \$us; $0,6 \%$ de 1501 a 2000 \$us y $0,3 \%$ más de $2000 \$$ us; siendo el promedio de 1245 \$us, Esta actividad es desarrollada en distintas modalidades: como personal en un $75,5 \%$, familiar en $23,2 \%$ y sociedad en 1,3\%., como se observan en las gráficas 2 y 3.

\section{Ingreso económico}

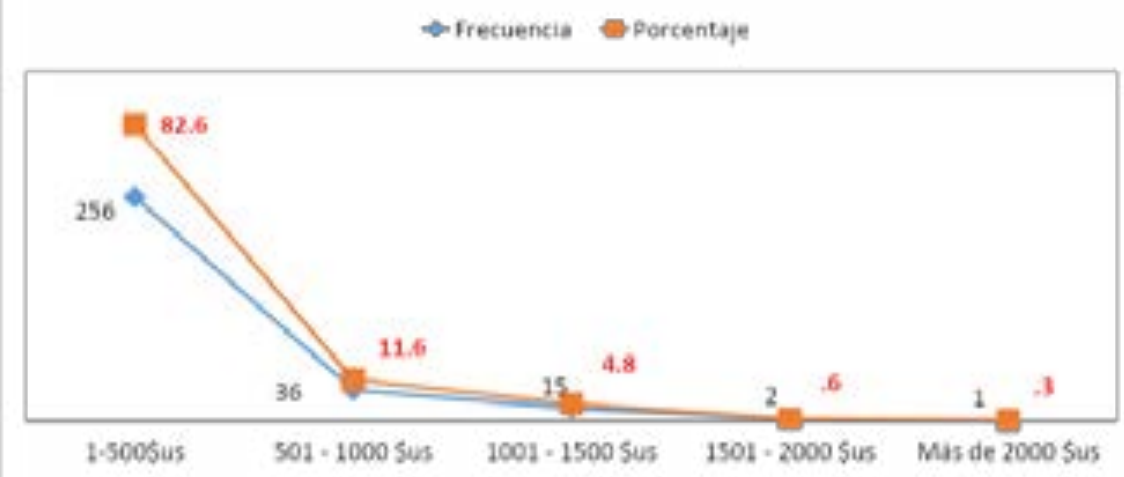

Figura 2. Ingreso económicos

Fuente: Encuesta dirigida a comerciantes informales de la ciudad de Riobamba, 2017 


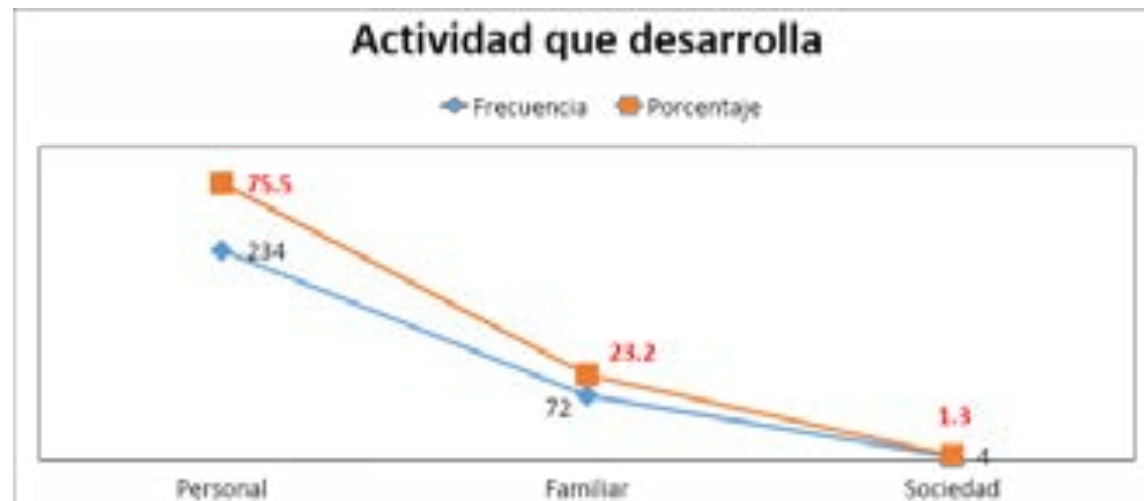

Figura 3. Actividad que desarrolla

Fuente: Encuesta dirigida a comerciantes informales de la ciudad de Riobamba, 2017

\section{Factores motivacionales para iniciar la actividad del comercio informal}

Los resultados de la investigación muestran que las razones que tuvieron los comerciantes para iniciar una actividad informal en su mayoría fueron porque quiere ser independiente (26,8\%); por necesidad (24,8\%); y no encontró trabajo asalariado $(24,8 \%)$, como se presenta en la tabla 3.

Tabla 3. Motivos para iniciar un negocio o actividad

\begin{tabular}{|l|l|l|}
\hline Motivos & $\begin{array}{l}\text { Frecuen- } \\
\text { cia }\end{array}$ & $\begin{array}{l}\text { Porcen- } \\
\text { taje }\end{array}$ \\
\hline No encontró trabajo asalariado & 77 & 24,8 \\
\hline $\begin{array}{l}\text { Obtiene mayores ingresos econó- } \\
\text { micos }\end{array}$ & 24 & 7,7 \\
\hline Quiero ser independiente & 83 & 26,8 \\
\hline Por tradición familiar & 31 & 10,0 \\
\hline $\begin{array}{l}\text { Por incremento del número de fa- } \\
\text { milia }\end{array}$ & 4 & 1,3 \\
\hline Por temporadas & 13 & 4,2 \\
\hline Por necesidad & 77 & 24,8 \\
\hline Otros & 1 &, 3 \\
\hline Total & 310 & 100,0 \\
\hline
\end{tabular}

Fuente: Encuesta dirigida a comerciantes informales de la ciudad de Riobamba, 2017

\section{Aplicación del análisis factorial para identificar factores causales}

El índice de Kaiser Meye Olkin de $\mathrm{KMO}=0.666$ indica que el modelo de factorización es pertinente y la prueba de Bartlelt muestra que el modelo es adecuado para explicar los datos. Los resultados de la matriz de componentes principales muestran que del total de factores utilizados (26 factores) se puedo reducir a 9 factores causales del comercio informal que se desarrolla. Asimismo, según la matriz de varianza, se puede identificar que los nueve factores reducidos explican el 63,77\%. Esta reducción permite identificar 
los factores más importantes que son causas de la actividad del comercio informal. En tal sentido, de acuerdo a la tabla 4 se muestra los resultados del análisis bajo el método de extracción de análisis de componentes principales y el método de extracción : varimas con normalización de káiser, donde se puede identificar que son 9 los factores que se encuentran relacionados con los factores causales del comercio informal.

Tabla 4. Resultados del análisis factorial - matriz de componentes

\begin{tabular}{|c|c|c|c|c|c|c|c|c|c|c|}
\hline \multicolumn{11}{|c|}{ Matriz de componente rotadoa } \\
\hline & \multicolumn{9}{|c|}{ Componente } & \multirow{2}{*}{$\begin{array}{l}\text { Comunali- } \\
\text { dad. } \\
\text { Extrac- } \\
\text { ción }\end{array}$} \\
\hline & 1 & 2 & 3 & 4 & 5 & 6 & 7 & 8 & 9 & \\
\hline Edad &,- 105 &,- 051 &,- 062 &, 004 &,- 041 &,- 628 & 018 &, 571 &, 065 & ,744 \\
\hline Estado civil &, 141 &,- 052 &, 050 &, 195 &, 003 & 616 &,- 059 & 193 & ,302 &, 575 \\
\hline $\begin{array}{l}\text { Identificación } \\
\text { étnica }\end{array}$ &,- 081 &,- 021 &, 062 & 020 &,- 134 & 075 &,- 014 & ,741 &,- 014 &, 584 \\
\hline Zona & 099 &,- 023 &,- 014 &,- 002 &, 859 &,- 104 &,- 013 &,- 006 &,- 082 & ,767 \\
\hline Residencia & 025 &, 021 &, 017 &, 045 &, 863 & 038 &, 003 &,- 137 & 103 & ,779 \\
\hline $\begin{array}{l}\text { Número de com- } \\
\text { ponentes o car- } \\
\text { ga familiar }\end{array}$ & , 127 &,- 128 &, 006 & 116 & , 132 &,- 520 &,- 224 &,- 078 &,- 009 & ,390 \\
\hline $\begin{array}{l}\text { Nivel de ins- } \\
\text { trucción }\end{array}$ &,- 021 & 195 &,- 087 &,- 077 &,- 014 & ,212 & ,593 &,- 217 &,- 229 & ,548 \\
\hline $\begin{array}{l}\text { Ingreso econó- } \\
\text { mico }\end{array}$ & ,017 &,- 178 & ,023 & ,099 &, 054 & ,095 & ,743 & 103 &,- 002 & ,617 \\
\hline $\begin{array}{l}\text { Lugar, local o } \\
\text { establecimiento } \\
\text { cuenta con ser- } \\
\text { vicio de agua } \\
\text { potable }\end{array}$ & ,877 & ,004 & ,012 & ,009 &,- 021 &,- 036 & ,067 & -155 & ,031 & 800 \\
\hline $\begin{array}{l}\text { Lugar, local o } \\
\text { establecimiento } \\
\text { cuenta con ser- } \\
\text { vicio de desague }\end{array}$ & ,759 & 011 &, 060 & ,085 & ,021 & ,019 &,- 039 &,- 240 & 177 & 679 \\
\hline $\begin{array}{l}\text { Lugar, local o } \\
\text { establecimiento } \\
\text { cuenta con ser- } \\
\text { vicios de electri- } \\
\text { cidad }\end{array}$ & , 747 &,- 075 &,- 078 & , 135 & ,082 &,- 119 &,- 156 & 106 &,- 061 & 648 \\
\hline $\begin{array}{l}\text { Lugar, local o } \\
\text { establecimiento } \\
\text { cuenta con ser- } \\
\text { vicios de telé- } \\
\text { fono }\end{array}$ & ,598 & ,259 & 118 &,- 019 & ,086 & 220 &,- 017 & ,062 &,- 028 & ,500 \\
\hline $\begin{array}{l}\text { Inversión en la } \\
\text { comercializa- } \\
\text { ción }\end{array}$ &,- 281 & , 134 & ,017 &,- 016 &,- 104 &,- 320 &, 554 & ,028 & ,234 & ,572 \\
\hline $\begin{array}{l}\text { Pertenencia a } \\
\text { una asociación }\end{array}$ & ,073 & 012 &,- 041 &,- 063 & ,025 & ,116 &,- 030 &,- 046 & ,871 & 787 \\
\hline $\begin{array}{l}\text { Considera que } \\
\text { la actividad del } \\
\text { comercio infor- } \\
\text { mal permite so- } \\
\text { brevivir }\end{array}$ & ,126 & 162 &,- 005 & 849 &,- 048 & ,037 &,- 072 &,- 041 &, 065 & ,777 \\
\hline
\end{tabular}




\begin{tabular}{|c|c|c|c|c|c|c|c|c|c|c|}
\hline $\begin{array}{l}\text { Considera que } \\
\text { la actividad del } \\
\text { comercio in- } \\
\text { formal permite } \\
\text { cubrir necesida- } \\
\text { des básicas }\end{array}$ & 020 & 097 & ,083 & ,884 &,- 027 & ,077 & 094 & ,024 &,- 010 & ,815 \\
\hline $\begin{array}{l}\text { Considera que } \\
\text { la actividad del } \\
\text { comercio infor- } \\
\text { mal permite re- } \\
\text { ducir la migra- } \\
\text { ción }\end{array}$ & ,042 &,- 079 & 253 & ,724 & 157 & -,101 & ,006 & ,068 &,- 115 & 648 \\
\hline $\begin{array}{l}\text { considera que la } \\
\text { actividad del co- } \\
\text { mercio informal } \\
\text { es una respues- } \\
\text { ta a la falta de } \\
\text { espacios de dis- } \\
\text { tribución }\end{array}$ &,- 060 & 059 & 612 & 207 & ,013 &,- 022 &,- 241 &,- 065 & ,222 & ,536 \\
\hline $\begin{array}{l}\text { considera que la } \\
\text { actividad del co- } \\
\text { mercio informal } \\
\text { es una respues- } \\
\text { ta al crecimien- } \\
\text { to de la pobla- } \\
\text { ción }\end{array}$ & 114 & 207 & 499 & 260 &,- 166 &,- 212 & ,196 & ,095 & ,238 &, 549 \\
\hline $\begin{array}{l}\text { Considera que } \\
\text { la actividad del } \\
\text { comercio infor- } \\
\text { mal es una res- } \\
\text { puesta al desco- } \\
\text { nocimiento de la } \\
\text { normas tributa- } \\
\text { rias }\end{array}$ & ,060 & 114 & ,766 & 058 & 100 &,- 009 & ,091 & ,107 &,- 162 & 663 \\
\hline $\begin{array}{l}\text { Considera que } \\
\text { la actividad del } \\
\text { comercio infor- } \\
\text { mal es por el } \\
\text { desconocimien- } \\
\text { to de la regu- } \\
\text { lación del uso } \\
\text { público }\end{array}$ & ,011 & ,043 & 832 & ,002 &,- 022 & 137 &,- 008 & ,047 &,- 052 & ,719 \\
\hline $\begin{array}{l}\text { Considera que } \\
\text { la actividad del } \\
\text { comercio infor- } \\
\text { mal no ayuda al } \\
\text { comercio formal }\end{array}$ &,- 156 & 299 & 237 & ,036 & 054 & 294 & ,034 & , 427 & -,116 & 457 \\
\hline $\begin{array}{l}\text { Considera que } \\
\text { la actividad del } \\
\text { comercio infor- } \\
\text { mal es por la fal- } \\
\text { ta de politicas } \\
\text { locales }\end{array}$ & ,074 & ,530 & ,438 & ,058 &,- 106 & 100, &,- 068 & -,017 & -,118 & ,522 \\
\hline $\begin{array}{l}\text { Considera que } \\
\text { pertenecer a } \\
\text { una asociación } \\
\text { le ayuda a desa- } \\
\text { rrollar su activi- } \\
\text { dad de manera } \\
\text { formal }\end{array}$ & 034 & ,706 & 052 & 190 & 203 &,- 023 &,- 029 &,- 027 &,- 063 & ,586 \\
\hline
\end{tabular}




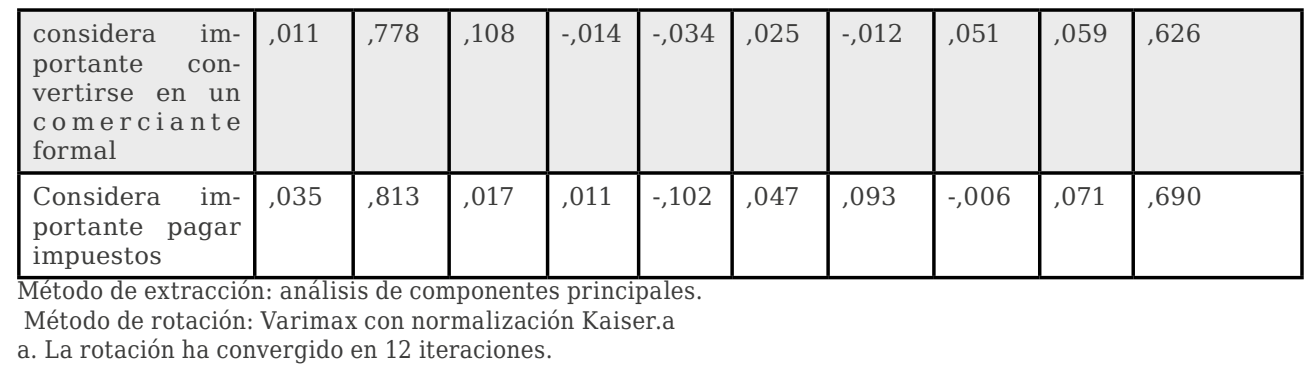

Estos factores están relacionados con la edad, la zona de residencia, el nivel de instrucción y el ingreso económico, los servicios básicos, la pertenencia a una asociación, con la sobrevivencia o necesidad, la migración.

\section{Aplicación de la regresión lineal}

La aplicación de la regresión lineal muestral que las variables como: Considera que pertenecer a una asociación le ayuda a desarrollar su actividad de manera formal, Estado civil, Género, Nivel de instrucción, Uso del servicio de agua potable, Número de componentes o carga familiar, Considera que la actividad del comercio informal es por el desconocimiento de la regulación del uso público, Tipo de actividad que desarrolla, Pertenencia a una asociación, Ingreso económico, Considera que la actividad del comercio informal permite sobrevivir, Edad, Considera que la actividad del comercio informal no ayuda al comercio formal, Considera que la actividad del comercio informal es una respuesta a la falta de espacios de distribución, Considera que la actividad del comercio informal permite reducir la migración, considera que la actividad del comercio informal es una respuesta al crecimiento de la población, Considera importante pagar impuestos, Considera que la actividad del comercio informal es por la falta de politicas locales, Considera que la actividad del comercio informal es una respuesta al desconocimiento de la normas tributarias, Considera que la actividad del comercio informal permite cubrir necesidades básicas, donde se puede identificar que este conjunto de factores explican el comercio informal en un 9,5\% lo que quiere decir que existen además otras variables que son las causas ( ver tabla 5).

Este resultado permite identificar que H2= la migración, el pago de impuestos, las necesidades básicas, la disponibilidad de espacios públicos son los principales factores que inciden en la actividad informal aunque no se observan como variables determinantes. 
Tabla 5. Resultado de la aplicación de la regresión lineal

\begin{tabular}{|c|c|c|c|c|c|c|c|}
\hline \multicolumn{8}{|c|}{ Resumen del modelob } \\
\hline \multirow[t]{2}{*}{$\begin{array}{l}\text { Mode- } \\
\text { lo }\end{array}$} & \multirow[t]{2}{*}{$\mathrm{R}$} & \multirow[t]{2}{*}{\begin{tabular}{l|}
$\mathrm{R}$ \\
cuadrado
\end{tabular}} & \multirow{2}{*}{$\begin{array}{l}\mathrm{R} \\
\text { cuadrado } \\
\text { ajustado }\end{array}$} & \multirow{2}{*}{$\begin{array}{l}\text { Error } \\
\text { es tá nd a r } \\
\text { de la } \\
\text { estimación }\end{array}$} & \multicolumn{2}{|c|}{$\begin{array}{l}\text { Estadísticas } \\
\text { de cambios }\end{array}$} & \multirow[t]{2}{*}{ Durbin-Watson } \\
\hline & & & & & $\begin{array}{l}\text { Cambio de } \\
\text { cuadrado } \\
\text { de R }\end{array}$ & $\begin{array}{l}\text { Cambio } \\
\text { en } \mathrm{F}\end{array}$ & \\
\hline 1 & ,308a & 095 & 033 & ,4592 & 095 & 1,519 & 1,805 \\
\hline \multicolumn{8}{|c|}{$\begin{array}{l}\text { a. Predictores: (Constante), Considera que pertenecer a una asociación le ayuda a desarrollar } \\
\text { su actividad de manera formal , Estado civil, Género, Nivel de instrucción, Uso del servicio } \\
\text { de agua potable, Número de componentes o carga familiar, Considera que la actividad del co- } \\
\text { mercio informal es por el desconocimiento de la regulación del uso público, Tipo de actividad } \\
\text { que desarrolla, Pertenencia a una asociación, Ingreso económico, Considera que la actividad } \\
\text { del comercio informal permite sobrevivir, Edad, Considera que la actividad del comercio in- } \\
\text { formal no ayuda al comercio formal, considera que la actividad del comercio informal es una } \\
\text { respuesta a la falta de espacios de distribución, Considera que la actividad del comercio in- } \\
\text { formal permite reducir la migración, considera que la actividad del comercio informal es una } \\
\text { respuesta al crecimiento de la población, Considera importante pagar impuestos, Considera } \\
\text { que la actividad del comercio informal es por la falta de politicas locales, Considera que la } \\
\text { actividad del comercio informal es una respuesta al desconocimiento de la normas tributarias, } \\
\text { Considera que la actividad del comercio informal permite cubrir necesidades básicas }\end{array}$} \\
\hline & & & & & & & \\
\hline
\end{tabular}

\section{CONCLUSIONES}

Por tanto, se concluye que el comercio informal se relaciona con las características generales de población y de la actividad comercial; y genera como consecuencia la reducción en la recaudación de impuestos.

Se concluye que las causas del comercio informal están relacionados con características sociales, económicas y de disponibilidad de servicios.

\section{REFERENCIAS BIBLIOGRÁFICAS}

Delgado, R., Abambari, M., \& Moreira , C. (2017). Efectos de la evasión en el impuesto a la renta, originado por el contrabando de mercaderías en la frontera Sur. Dominio de las Ciencias, 275-284.

ENEMDU, INEC. (2018). Tabulados Encuesta NAcional de Empleo, Desempleo y Subempleo (ENEMDU). Disponible en www.ecuadorencifras.gob.ec: INEC.

Figueroa-Sierra, N. (2012). La elusión y evasión fiscal. Revista Avances Vol. 14, 374.

Henríquez, J. Y. (2015). EVASIÓN TRIBUTARIA: ATENTADO A LA EQUIDAD. 171.

León, M. O. (2014). ELUSIÓN O EVASIÓN FISCAL. Revista Iberoamericana de Contaduría, Economía y Administración , 5.

Merchán, M., \& Velásquez, N. (2015). La evasión y elusión tributaria de las MYPE en las empresas del sector comercio-rubro abarrotes del distrito de Chimbote, 2014. In Crescendo. Derecho, 19-27.

OIT. (2018). Mujeres y hombres en la economía informal: Un panorama estadístico. Ginebra: OIT.

\section{Cumbres}


Ordoñez. (Abril de 2010). Evasión tributaria y redistribución de los ingresos: Enfoque de un Modelo de equilibrio general tributario. 12.

Paredes, P. (2016). Evasión tributaria vs. Mecanismos de control implementados por la administración pública. Retos, 181-198.

Quintanilla, E. (2014). Repositorio Académico USMP. Obtenido de Repositorio Académico USMP: http://www.repositorioacademico.usmp.edu.pe/bitstream/usmp/1106/1/quintanilla_ce.pdf

Quispe, G., Tapia, M., Ayaviri, D., Villa, M., Borja, M., \& Lema, M. (2018). Causas del comercio informal y la evasión tributaria en ciudades intermedias. Espacios, 4.

Quispe, Gabith; Tapia, Marieta; Ayaviri, Dante; Villa, Marlon; Borja, Maria; Lema, Magdala. (2018). Las causas del comercio informal y la evasión tributaria en ciudades internedias. Revista Espacios, 4.

Real, M., \& Navarrete, C. (2018). Los paraísos fiscales y la elusion tributaria en el Ecuador. Dilemas Contemporáneos: Educación, Política y Valores. , 1-15.

Romero, V. (2018). Las brechas de recaudación tributaria del impuesto al valor agregado en el sector societario y su impacto en el presupuesto general del estado ecuatoriano. Observatorio de la Economía Latinoamericana.

Rua, W. ( 2016). El concepto de evasión y elusión . 73.

Sandoval, G. (2014). La informalidad laboral: causa generales. Equidad Desarrollo, 9-45. https://dialnet.unirioja.es/descarga/articulo/5166528.pdf.

Suárez, E. (2017). Motivos y consecuencias de la evasión tributaria en ... Repositorio UCV. Obtenido de Motivos y consecuencias de la evasión tributaria en ... Repositorio UCV.: http://repositorio.ucv.edu.pe/bitstream/handle/ UCV/4595/Suar\%C3\%A9z_GED.pdf?sequence=1 